\title{
Research on Construction of Advanced English Teaching Based on Production-Oriented Approach
}

\author{
Xinmei Wang \\ Shandong University of Finance and Economics, Shandong, China
}

\begin{abstract}
In view of the separation of learning and application in foreign language teaching in China, a Production-Oriented Approach theory (POA theory) of integrating learning and application in foreign language teaching is proposed. The theory takes unit tasks with potential communicative value as the teaching target, and students selectively learn input materials under the guidance of teachers, and finally achieve effective output and complete communicative tasks. This paper tries to apply POA theory to Advanced English Teaching by decomposing the overall goal to sub-goals within a unit task, so as to stimulate students' enthusiasm for learning and willingness to produce.
\end{abstract}

Index Terms-production-oriented approach, input, output, Advanced English Teaching, unit task

\section{INTRODUCTION}

With the progress of teaching concepts and the enrichment of teaching methods, foreign language teaching becomes more student-centered and begins to focus on cultivating the output ability of language learners. In recent years, the Production-Oriented Approach theory (POA theory), a foreign language teaching theory with Chinese characteristics, has been widely used in all kinds of foreign language classroom teaching. POA theory can effectively improve the learning effect of language learners and improve the separation of learning and application (Wen, 2017). Some studies have preliminarily proved that POA theory is applicable to classroom teaching of intensive reading for English majors. It can stimulate students' enthusiasm for learning and willingness to produce. This paper tries to apply POA theory to Advanced English Teaching for juniors majoring in Business English.

\section{INTRODUCTION OF POA THEORY}

After more than ten years of development, POA theory has formed a theoretical system of foreign language teaching. It is a new foreign language teaching theory proposed by Professor Wen Qiufang. The theory takes unit tasks with potential communicative value as the teaching target, and students selectively receive input materials under the guidance of teachers, and finally achieve effective output and complete communicative tasks (Wen, 2015).

POA theory consists of three parts: teaching concept, teaching hypothesis and teaching process (Wen, 2015).

The teaching concepts include learning-centered theory, the theory of integration of learning and application, cultural exchange theory and key competence theory (Wen, 2015). Learning-centered theory advocates that all classroom teaching activities are to promote effective learning; the theory of integration of learning and application holds that input and output of relative materials should be integrated in classroom teaching and learning. Cultural exchange theory emphasizes the integration of cultural learning in language teaching to make cultural communication more harmonious and smooth. Key competency theory focuses on students' ability to solve complex problems in uncertain and complex situations.

Teaching hypotheses include output-driven hypothesis, input enabling hypothesis, selective learning hypothesis and evaluating hypothesis (Wen, 2015). Output-driven hypothesis believes that learners can realize the difficulty of output when trying to produce so that they can increase their learning motivation. Input enabling hypothesis advocates that input of materials should serve output objectives. Under the output-driven conditions, the combination of input and output tasks can effectively promote the smooth completion of output tasks. Selective learning hypothesis emphasizes the selection of learning materials from the input materials according to the needs of output goals. This kind of goal-oriented learning can better optimize learning effects. It is pointed out that assessment is the key point of strengthening and sublimating students' learning, and evaluation and learning should be fully combined (Chang, 2017).

Its teaching process includes motivating, enabling and evaluating (Wen, 2015). Teacher plays the role of guiding, designing and supporting during the whole process. Motivating process includes three main steps: teacher presents communicative scenes; students try to produce and teacher explains teaching objectives and output tasks. Enabling process includes three main steps: the teacher describes the task of output; the students selectively adopt input materials while the teacher gives guidance and checks; and the students produce while the teacher gives guidance and checks. The main task of enabling process is to provide support for the successful completion of output tasks and facilitate the 
occurrence of effective learning. Evaluating process refers to the evaluation of output, which is divided into immediate evaluation and delayed evaluation (Qiu, 2020). Immediate evaluation refers to the evaluation of students' output at any time in the teaching process. Delayed evaluation refers to the evaluation of the output tasks completed by students after class (Qiu, 2020).

Advanced English is the main course for English majors in Chinese universities. Traditional teaching takes teachers as the center of classroom activities, and carries out multi-dimensional teaching activities such as vocabulary, grammar, rhetoric, style and culture, so as to improve the comprehensive abilities of learners in listening, speaking, reading, writing and translation. This teaching mode attaches importance to the breadth of teaching content and the depth of knowledge. However, due to the lack of effective communication training, students can not apply the knowledge they have learned, so its teaching validity has been criticized. Different from traditional foreign language teaching, POA theory sets "unit task" at the beginning of each unit learning, which is both the output task of the unit and its teaching objective. This is of great value to Advanced English learning for English majors. In the author's opinion, "unit task" can be added separately after the end of preliminary teaching, so as to realize the combination of POA and traditional teaching mode. Based on the above ideas, this paper takes Face to Face with Hurricane Camille in Advanced English as an example to carry out the POA teaching.

\section{DESIGN AND IMPlementation OF TEACHING PROCESS BASED ON POA THEORY}

Guided by the teaching concept of POA theory, the teaching is designed by following the three steps of Motivating, Enabling and evaluating. The teaching objects are one class of juniors majoring in Business English, a total of 22 students.

\section{A. Motivating Process}

Motivating Process should meet the three targets of authenticity of communication, cognitive challenge and the appropriateness of output (Qiu, 2020). Before beginning a new unit, first of all, the teacher determines output targets and tasks. The topic of discussion should be challenging. Then teacher designs "output" scenarios according to goals and tasks and presents students with communication scenarios they may encounter in their studies and future work. Design of output scenarios should have four elements: topic, purpose, identity and occasion, which are both different and closely related. Secondly, teacher let students try output tasks, so that they can truly feel that the completion of output tasks is not easy, so as to stimulate their desire to learn. Through students' tentative output, teacher helps analyze output difficulties and find their needs and barriers in learning. Finally, teacher sets the appropriate output objectives and output tasks according to the theme of each unit. Teaching objectives can be divided into communicative objectives and language objectives (Qiu, 2020). Language objectives must serve communicative objectives. In order to reduce the difficulty of completing the output task and increase students' confidence and sense of achievement, teachers can design several sub-tasks.

Face to Face with Hurricane Camille tells how the Koshaks, an ordinary family in Mississippi, the United States, fought against that devastating Hurricane Camille in 1969. Each unit in Advanced English of the author's department takes 8-12 teaching hours. The object of this teaching experiment is 22 juniors majoring in Business English. Before this, the author has implemented the preliminary basic teaching of the text content for three weeks with a total of 6 teaching hours, and the vast majority of students performed well in learning.

Motivating Process in POA theory is a process to stimulate students' learning initiative by trying output, which includes three steps: teacher presents communicative scenes; students try output; teacher explains teaching objectives and output tasks (Qiu, 2020).

The first, teacher presents communicative scenes. In motivating process, teacher designs output tasks to present real and communicative scenarios to students. The design of output tasks, on one hand, should be slightly higher than the real foreign language ability of students, so that students can see the hope of successful communication, and on the other hand, should also create "gaps" to stimulate their desire and enthusiasm for learning. This text contains a large number of descriptions of disaster brought by heavy winds and floods, so the author designs the output task of "description of disaster scenes" in one video The Raging Planet---Hurricanes in the form of oral presentation.

The second, students try output. First of all, the author introduced the general content of the video The Raging Planet---Hurricanes to the class, and played the video clips from the very beginning to 5 minutes 59 seconds and 26 minutes 30 seconds to 32 minutes 29 seconds with the projector, which lasted about 10 minutes. Then the students were divided into three grades of "excellent", "average" and "poor" according to the difference of communication ability in English, and each student was invited to try to describe what he/she saw in the video. The results show that the students with strong communication ability can describe the disaster scenes in the video roughly, and can grasp some key scenes and use descriptive language to describe them in general, but the sentence pattern is too simple, the words are not precise enough, and the description is not detailed enough. Students with average communication ability can give a general description, but have difficulty in choosing vocabulary and sentence patterns, and even cannot complete the description. The poor students could only speak fragmentary words and failed in their attempts to fulfill the output tasks.

The third, teacher explains teaching objectives and output tasks. After the students tried the preliminary output task, 
most of the students' attention was successfully aroused and they obviously felt the gap between their communication ability and the output task. As a result, their desire to learn was stimulated. The author organized a group discussion around the focus of what are the obstacles in the current output task, and let the students find out what is the difficulty in completing the output task. The following are typical feedbacks:

The lack of vocabulary makes me difficult describe it.

I don't know which word I should use to describe the disaster.

I feel easy to describe, but when I opened my mouth, I found I am in chaos and I don't know how to describe.

According to the feedback of students, it is difficult to complete the overall output task, so it can be divided into several sub-goals that are relatively easy to accomplish. In this way, students can gradually complete the overall goal. According to the students' output difficulties, the author further decomposed the overall goals of the unit. The overall goal of the output task is to describe destructive forces of hurricanes and how people prepare to fight against Hurricane. The sub-goals are the description of scenarios (description of trees, ocean, the sound they heard, the houses, etc.) when Hurricane comes, preparation work of local citizens (fasten the house, retreat to the inland areas, etc.), and relative terms about narration.

In this way, by reducing the difficulty of the task, students could follow the sequence of description from decomposed tasks to sub-goals, and then to the overall goal, and achieve the overall goal step by step.

\section{B. Enabling Process}

In the whole POA teaching process, enabling Process is the most important, the most complicated and the most difficult part. Wen Qiufang (2015) believes, "To complete a productive task successfully, there needs at least contents, language and discourse structure" (p. 49). The requirement of language enabling in POA theory is that students choose the language form required by the output task according to the input materials, and apply the target language to the output tasks. In terms of the output task of this unit, students' understanding of content comes from video materials. In addition, the decomposition step of the overall goal of the unit has provided the discourse structure of the output task in the form of oral presentation. Therefore, according to the principle of selective learning, the author set the enabling aim of this output task as the language form, namely words, phrases and sentence patterns.

\section{Design of Enabling Activity}

In the design of enabling activity, teacher mainly guides students to selectively absorb input materials. The enabling process in this classroom teaching is divided into three steps. The first step is to adopt the mode of "bundling learning" to input materials and enable the students to learn at the same time. The first gap that students face in output task is terminology about hurricane and disasters, which is a prerequisite for completing the sub-tasks. The input material in this step are: terms about narration (narration, background, conflicts, plot, characters, climax, protagonist, antagonist, etc.); terms about hurricane (Incipient hurricanes, typhoon, cyclone, diameter, the Beaufort scale, moist air and converging equatorial winds, thunderstorms, eye wall, rain bands, powerful, deadly, destructive, casualties, etc.), and preparation work (fasten, retreat, ride out, batten down, etc.)

From the observation of the author, students responded positively to the input material and received it well. In order to further understand the effect of the materials on solving the "gap" of students' output, the author randomly interviewed several students, and received feedback generally as "very helpful", and "reduced the difficulty of the task" and so on. This proves that the input materials correctly met the needs of students in the process of completing the output task, and the enabling effect of the language material is fully reflected.

The second step is to make students be familiar with the words, phrases and sentence patterns that describe disasters caused by hurricanes. POA theory insists that the supporting function of teachers should decrease with the increase of students' cognitive ability in the enabling process. Therefore, in this step, the author no longer directly provides students with the input materials needed to complete the overall task of the unit, but let them try to find out the content needed in the text to complete the communicative task, so as to improve students' sense of responsibility for learning and initiative to participate in classroom teaching activities. Therefore, the author designed a classroom activity.

First of all, the description of disaster caused by hurricane Camille in the text is classified. The first type is description of "attacks of hurricane", the second type is description of "house attacked", the third type is "description of characters involved in the story", that is, the behavior of people in the wind, their psychological description, etc. The fourth type is the description of the horrible sound of strong winds. 22 students of the class are divided into four groups, and each group get one task randomly. The student, who first found the relative descriptive words related to his/her group task, could tell the teacher the position of them in the text, and at the same time, the teacher guides other students to find relevant descriptions in the text and mark them. Then the next student did the same until all the input materials involved in the text has been found. The teacher controlled the duration of the activity, and the group that accurately found more and finished faster won. At the end of the activity, the author set up a test to classify, sort out and restudy the task in the form of filling blanks. The main purpose of this session is to help students deepen their memory, clarify their thoughts, and further clarify which materials can serve the output task. Since students are already familiar with the relevant input materials in this activity, the blank filling exercise is generally completed well.

The third step is output practice and checks. After students have completed selective learning, teachers can have students try output practice to check the degree and effect of language enabling. According to the progressive principle, 
output practice should follow the sequence from "word" to "sentence" to "paragraph", from "decomposition task" to "sub-goal" to "overall goal". The author adopted the method of "group discussion plus individual presentation", and each student in the group first tried to describe the scene when hurricane comes, and the damage caused by severe weather such as strong wind and rampaging flood). With previous input material as a support, this decomposition task is relatively easy. In the output attempt of decomposed task, basically all students can describe the required content, and some students with better foundation have very good output. This is followed by description of preparation work and destructive power of hurricanes, which completes the transition from decomposing tasks (sentences) to sub-goals (sentence groups). After group practice, 4 students were selected as group representatives to try the output of the sub-target, and other students recorded the language characteristics and language mistakes they reported orally. Through the preparation of decomposed tasks, the student performed well in the output practice of sub-targets. In a randomly selected sample, the author analyzed the student's output performance to test the influence of students' selective learning on language output, and found that the input material accounted for $29.8 \%$ of the text. It can be seen that the student has a good command of the input materials in the enabling stage and can use them in his own language output. Since the overall goal of the unit can be achieved by the combination of the sub-goals of "scene description", "preparation description" and "character description", without the need for new input materials and further selective learning as auxiliary and support, the author believes that the successful output of the sub-goals has proved that students have completed the output of the overall goal of the unit.

\section{Summary of the Enabling Activity}

Wen Qiufang (2015) points out the principles of enabling effectiveness: progressiveness, precision and diversity. The author will summarize how to ensure the effectiveness of this classroom teaching from these three aspects.

First of all, this enabling activity embodies the principle of progressiveness. Language learning has its own rules, and should follow the rule of progressiveness. In the whole enabling process, the teacher first provided hurricane-related terms in form of vocabulary, and the students' cognitive difficulty in language processing of the input materials was relatively low. Then in the classroom activity, the students' input materials were the phrase structure describing disasters caused by hurricanes, and the cognitive difficulty of language processing increased.

In the output practice, the difficulty is further increased from the sentence output of the decomposing tasks to the sentence group output of the sub-targets, and the cognitive process of "word, phrase, sentence, and sentence group" is realized. The difficulty of students' processing of input materials is gradually increasing. In addition, in the process of selective learning, the teacher provides input materials for "bundled learning" at the beginning, and the students find the input materials needed for output in the text by themselves. Thus the supporting function of teachers gradually decreases, and the independent learning ability of students gradually increases.

Secondly, in this classroom teaching, accuracy of enabling activity is mainly reflected in two aspects. First, accurate input matches teaching objectives. All input information and enabling activities used are for output services, and all information that does not help output is not within the scope of teaching. Second, accurate input fills the "gap" of students' output. Input information and enabling activities are aimed at the "shortcomings" of students' output, which greatly improves the efficiency of students' selective learning.

Finally, diversity of enabling activities is mainly reflected in input modes and input activities. There are three modes of classroom teaching, namely text learning, teacher's explanation and video watching. In addition, in the input activity, the class as a whole participated in that activity. There are group discussions and individual presentations, and input activities are diverse in form and rich in content, which not only improves students' interest and participation, but also greatly improves their learning efficiency.

\section{Evaluating Process}

The evaluating methods in POA theory include immediate evaluation and delayed evaluation. Although POA attaches more importance to delayed evaluation, since the output form of this classroom teaching is oral presentation, the author chooses immediate evaluation to check students' output.

Firstly, the teacher determines the evaluation focus. After the group presentation, the author carried out a discussion among the groups to highlight the shortcomings of the oral output. The following are representative feedbacks in the mutual evaluation:

"The description is too general, as if not as vivid as that in the movie."

"The expression is confusing and the train of thought is not clear."

"Vocabulary is scarce. Although the main content is said, the words are always repeated."

"It's not specific and vivid enough, the effect is not as good as that in the movie."

According to the output performance of the students and the feedback of the students, the author determined that the focus of the evaluation was the expressive effect of oral presentation.

Secondly, in the evaluating process, the teacher first listed vivid and exquisite sentences describing disaster in the text, and then organizes class discussion to guide students to think about the characteristics and expression methods of these sentences. Finally, the evaluation criteria are "use of rhetorical devices" and "increase of the detailed description of typical characters (actions, language, psychology, etc.)". An attempt was made to reproduce under these two evaluation criteria, and it was found that their oral reports showed significant improvement in verbal expression. 
The process of immediate evaluation is also a process of secondary enabling process. Through further selective learning of input materials, students improve the effect of output and maximize the value of input materials in teaching activities.

The effect of advanced English teaching under the guidance of POA theory has proved that students' classroom participation and learning efficiency have been significantly improved, and their language output ability has been improved, which helps to avoid the separation of learning and use in English teaching. These practical experiences have certain reference value for the reform of advanced English teaching.

\section{TEACHING REFLECTION}

Firstly, the teaching experiment shows that the Advanced English Teaching based on POA theory is feasible in practical teaching. The atmosphere in classroom teaching is positive and students are enthusiastic about learning.

Secondly, POA theory can motivate students to study actively. Driving tasks stimulate students' learning enthusiasm. In the implementation process of POA theory, in order to promote the transformation of students' receptive knowledge into productive knowledge, create more opportunities to use language, divide the output task with communicative value into three small tasks, reduce the difficulty of output, and facilitate students to complete the output task smoothly.

Thirdly, POA theory challenges teachers' teaching ability and promotes the improvement of students' output quality and ability. In the teaching process, under the guidance and help of teachers, students' self-confidence is enhanced and they overcome the learning anxiety. According to the POA theory, the design of output tasks based on the theme of each unit gives full play to teachers' leading role. With output task as a driving force, teacher carefully chooses the listening and reading materials, guides the student to carry out selective learning, combines the input materials and output students, which promotes their learning, and at the same time saves time of classroom teaching and improves the teaching effect.

\section{CONCLUSION}

POA theory is a foreign language teaching theory suitable for China's national conditions, and its main purpose is to solve the problems of "low efficiency" and "separation of learning and application" in English teaching. In order to solve the existing problems in English teaching, the author tries to design the teaching process based on POA theory in classroom teaching. The teaching practice shows that students approve of POA-based English teaching and have a high degree of satisfaction with it. POA theory changes students' behavior, improves their learning autonomy, makes their classroom performance more positive and active, gives full play to their potential, and improves their learning ability. This paper makes a practical exploration of POA theory, enriches the research of English teaching and provides some theoretical and practical experience for English teaching. However, due to the preliminary attempt to study the application of POA theory in practical teaching, the teaching design, teaching evaluation and other aspects are still not perfect, and further in-depth and systematic research should be carried out in the future.

\section{REFERENCES}

[1] Chang Xiaoling. (2017). "chan chu dao xiang fa" de jiao cai bian xie yan jiu [A Study on the Textbook Compilation by Using "Production-Oriented Approach"]. Modern Foreign Language, 40(3): 59-68.

[2] Qiu Lin. (2020). "chan chu dao xiang fa" ying yong zhong de jiao shi fa zhan: mao dun yu dui ce 「Teacher Development in Application of "Production-Oriented Approach": Contradictions and countermeasures]. Chinese Foreign Language, 17(1): 68-74.

[3] Qiu Lin. (2020). "chan chu dao xiang fa" cu cheng huan jie she ji biao zhun li xi [Design of Enabling Process in Applying "Production-Oriented Approach"]. Foreign Education Research, 3(5): 12-19.

[4] Wen Qiufang. (2015). Gou jian "chan chu dao xiang fa" li lun ti xi [Construction of "Production-Oriented Approach"]. Foreign Language Teaching and Research, 23(4): 47-58.

[5] Wen Qiufang. (2017). "chan chu dao xiang fa" de zhong guo te se ["Production-Oriented Approach" with Chinese Characteristics]. Modern Foreign Language, 44(3): 69-71.

Xinmei Wang was born in Dezhou, China in 1977. She received her master degree in linguistics from Chongqing University, China in 2004.

She is a College English teacher for English majors in Shandong University of Finance and Economics in Jinan, has been teaching English majors for more than 10 years. The courses she has taught include Advanced English, Basic English Writing, etc. During this decade, she published several papers. Her research field is theoretical linguistics. 